\title{
Piezoelectric surgery versus conventional rotary surgical technique for surgical removal of impacted mandibular third molars: A prospective study
}

\author{
Pradeep PS ${ }^{1}$, Sunil Sathigrama Malegowda ${ }^{2, *}$, Muhsina K ${ }^{3}$, Pravitha S Anchan ${ }^{4}$, Asal Irfan P \\ ${ }^{1}$ Associate Professor, ${ }^{2}$ Reader, ${ }^{\mathbf{3 , 5}}$ Junior Resident, ${ }^{4}$ Senior Resident, ${ }^{\mathbf{1 , 3}, 4,5}$ DM Wayanad Institute of Medical Sciences, Wayand \\ Kerala, Coorg Institute of Dental Sciences, Virajpet, Coorg, Karnataka, India
}

*Corresponding Author:

Email: sunilsmomfs@gmail.com

\begin{abstract}
Introduction: Impacted third molar surgery is a frequently performed procedure in clinical work. Surgical removal of impacted third molars is often required in symptomatic conditions. Conventional rotary cutting instruments may be potentially injurious, so piezosurgery has been introduced as a new osteotomy technique with promising outcome. Purpose of this study was to compare techniques of surgical removal of impacted mandibular third molars using piezosurgery versus the conventional surgical technique. The parameters were time required, patient satisfaction, severity of pain and mouth opening postoperatively.

Materials and Methods: This prospective study consisted of 20 medically fit patients between $18-40$ years of age with bilateral impacted mandibular third molars from both the genders. On one side surgical extraction was done using conventional rotary technique and contra lateral side was treated using piezosurgery (split mouth study design). Statistical analysis was done between these two techniques for patient satisfaction, duration of surgery, pain perception and trismus.

Results: Piezoelectric surgery took more time than rotary, but patient satisfaction, pain, mouth opening was statistically poor with conventional rotary technique.

Conclusion: Piezoelectric device is a promising, meticulous, innovative ultrasonic technique for safe and effective bone removal when compared with rotary technique.
\end{abstract}

Keywords: Piezoelectric surgery, Rotary surgical technique, Surgical removal, Mandibular impacted third molar.

\section{Introduction}

Dentoalveolar surgery and especially surgical removal of third molar teeth continues to be the most common surgical procedure performed in the speciality of oral \& maxillofacial surgery. The surgical removal of third molar teeth may result in a number of complications including pain, trismus, swelling, bleeding, alveolar osteitis, nerve dysfunction or even infections. ${ }^{1}$ Several factors have been reported to be associated with these complications which includes age and health of the patient, use of oral contraceptives, smoking, poor oral hygiene, degree of impaction, duration of the procedure, various surgical techniques, inadequate irrigation and iatrogenic factors. Factors contributing to the occurrence of pain and oedema after $3^{\text {rd }}$ molar extractions are complex, but are related to the inflammatory process that is initiated by surgical trauma. $^{2}$ Injury to tissue during surgical procedure results in the release of chemical mediators of inflammation. ${ }^{3}$ Trismus might occur as a direct consequence of Masseter muscle trauma, due to prolonged surgery or due to excessive periosteal stripping, having as a consequence of diffused swelling. ${ }^{4}$ Initially bone removal was performed using chisel and mallet, which later benefitted from the introduction of rotary devices to oral surgery, becoming less time consuming procedures with increased comfort to the patient and subsequent better technical and biological outcomes due to a more accurate cut definition. ${ }^{5}$ Rotary speed ranging from 15,000 to 25,000 $\mathrm{rpm}$ used in oral surgery produces macrovibration and requires a supplemental force to oppose the rotating couple of the instrument. It generates considerable amount of heat, due to which so a profuse copious irrigation has to be maintained to prevent any thermal necrosis of bone. ${ }^{6}$ Piezosurgery is a new innovate technique used to perform safe and effective osteotomies using piezoelectric ultrasonic vibrations. It was first developed by Italian oral surgeon Tomaso Vercellotti in 1988 to overcome traditional instrumentation. ${ }^{7}$ A frequency of $25-29 \mathrm{kHz}$ is used because the micromovements created at this frequency cut only mineralized tissues. The amplitude of these microvibrations range from $60-200 \mathrm{~mm} / \mathrm{sec}$ which allows a clean, precise cut and works selectively, being inert against soft tissues, including nerves and blood vessels. $^{8}$ This study compares the two different instruments i.e. piezoelectric and rotary bur for removal of impacted mandibular third molars for evaluating the time required, patient satisfaction of the procedure intra-operatively, the severity of pain and mouth opening postoperatively.

\section{Materials and Methods}

Study design: Sample size was determined to be 20 patients. All patients were informed about the study and consent was taken for the same. Routine hematological investigations were carried out. Preoperative orthopantomogram and intraoral periapical radio figures were taken. The patients were subjected to removal of impacted mandibular third molars using piezoelectric and rotary bur. The study was conducted 
to compare surgical and post-surgical outcome of impacted third molar removal using piezoelectric on one side and rotary bur on contralateral side. Internal ethics committee for human studies, of the institution has approved this study.

Intra-operatively, the time taken and patient satisfaction of the procedure was evaluated. Post operatively, patients were evaluated for pain using a feedback form of visual analog scale for a period of 7 days, mouth opening examined clinically on day 3 , day 5 and day 7.

Materials: Rotary devices consist of hand piece and foot switch which are connected to main power unit. A hand piece is a device for holding rotating instruments, transmitting power to them, and positioning the mintraorally. Rotary speed of around 35,000 rpm is used. Rotary burs 702 and 703 were used.

Piezoelectric device consists of a hand piece and a foot switch that are connected to the main power unit. This has a holder for the hand piece, and contains irrigation fluids that create an adjustable jet for 0$61 \mathrm{ml} / \mathrm{min}$ through a peristaltic pump. A frequency of $25-29 \mathrm{kHz}$ with a microvibration of $60-200 \mathrm{~mm} / \mathrm{sec}$ is used with a boosted working mode. Piezoelectric burs SL 1, SL 2, \& SL 3 were used.

\section{Inclusion criteria}

1. Patients with bilateral impacted lower teeth

2. All patients ASA I and aged over 18-40 years

3. Impacted mandibular third molars under following category
a) Mesioangular
b) horizontal
c) Vertical
d) class I
e) class II
f) position $\mathrm{A}$
g) position $\mathrm{B}$

were included in the study based on the radiographic interpretation.

\section{Exclusion criteria}

1. Patients who were not interested to enroll in the study.

2. Patient with uncontrolled systemic illnesses involving bleeding, immunity, and endocrine system.

3. Pregnant or lactating women

4. Mandibular third molar under following category class III, position $\mathrm{C}$, and distoangular.

\section{Surgical procedure}

All the patients underwent surgical removal of impacted mandibular third molars under $2 \%$ Lignocaine with 1:200000 adrenaline. Inferior alveolar, lingual and long buccal nerve block was administered. Modified Terrance Ward incision was given. Full thickness mucoperiosteal flap was raised and retracted using Austin's retractor. On one side, bone was removed using rotary device with \#702 or \#703 bur and constant irrigation was done using sterile isotonic saline solution to reduce the heat generated during bone removal. After around 10 to 15 days, using SL 1, SL 2, \& SL 3 burs, bone was removed using piezoelectric device on contralateral side. Guttering technique was adapted on both the sides. The teeth were removed in toto. The irregular bone and gingival margins were parried; the wound was irrigated with sterile saline solution. Flaps were repositioned and sutured using 3-0 black braided silk. Post operatively, all patients received amoxicillin $500 \mathrm{mg}$ tid and diclofenac sodium $50 \mathrm{mg}$ tid for 3 days. Postoperative instructions were given and the sutures were removed on the $7^{\text {th }}$ day.

\section{Evaluation}

a) Intra-operatively, time required for the procedure was evaluated i.e., starting from time of bone guttering until the tooth elevation from its socket.

b) Patient satisfaction of the individual procedure was evaluated intra-operatively and graded using a scale. (Table 1)

Table 1: Patient satisfaction scale

\begin{tabular}{|c|c|}
\hline Grade & Patient Satisfaction \\
\hline 1 & Very Satisfied \\
\hline 2 & Fairly Satisfied \\
\hline 3 & Fairly Unsatisfied \\
\hline 4 & Very Unsatisfied \\
\hline
\end{tabular}

c) Post operatively, patients were educated regarding the pain feedback form and asked to provide information regarding pain. The degree of pain were recorded for a period of 7 days with reference to predefined values on VAS (visual analog scale).

d) For mouth opening, Inter-incisal distance is measured preoperatively, and postoperatively on day 3 , day 5 and day 7 . (Table 2)

Table 2: Grading of mouth opening (interincisal distance)

\begin{tabular}{|l|c|}
\hline Grade & Mouth Opening in MM \\
\hline 0 & $>35$ IS NORMAL \\
\hline 1 & $25-30$ \\
\hline 2 & $20-25$ \\
\hline 3 & $15-20$ \\
\hline 4 & $<10$ \\
\hline
\end{tabular}

\section{Results}

The present clinical study compares efficacy of piezoelectric and rotary bur in surgical removal of impacted third molars. The study was done in Department Of Oral and Maxillofacial Surgery, Coorg Institute of Dental Sciences, Coorg. Patients belong to age group 19 to 34 years, out of which 11 were males and 9 were females. Intra-operatively, the time taken 
and patient satisfaction of the procedure was evaluated and post operatively, clinical assessment of mouth opening was done on day 3 , day 5 and day 7 , correlating with that of preoperative value. Pain was evaluated subjectively using feedback form of visual analog scale for a period of 7 days.
1. The time taken for removal of impacted tooth using rotary bur was much less $(25.15 \pm 6.74 \mathrm{~min})$ compared to that of piezoelectric device $(50.30 \pm$ $20.51 \mathrm{~min}$ ). Student $\mathrm{t}$ test (paired) was used for statistical analysis, as shown in Table 3 and Fig. 1.

Table 3: Comparison of time taken in minutes between piezoelectric and Rotary Surgery

\begin{tabular}{|l|c|c|}
\hline Time taken in minutes & Piezoelectric & \multicolumn{1}{c|}{ Rotary } \\
\hline Min-Max & $15-88$ & $15-41$ \\
\hline Mean \pm SD & $50.30 \pm 20.51$ & $25.15 \pm 6.74$ \\
\hline $95 \%$ CI & $15.0-88.0$ & $15.0-41.0$ \\
\hline Inference & $\begin{array}{l}\text { Time taken is significantly less in Rotary (25.15 minutes) } \\
\text { compared to Piezoelectric (50.30) with } \quad \mathrm{t}=7.130 ; \\
\mathrm{P}<0.001^{* *} \text { Student t test (Paired) }\end{array}$ \\
\hline
\end{tabular}

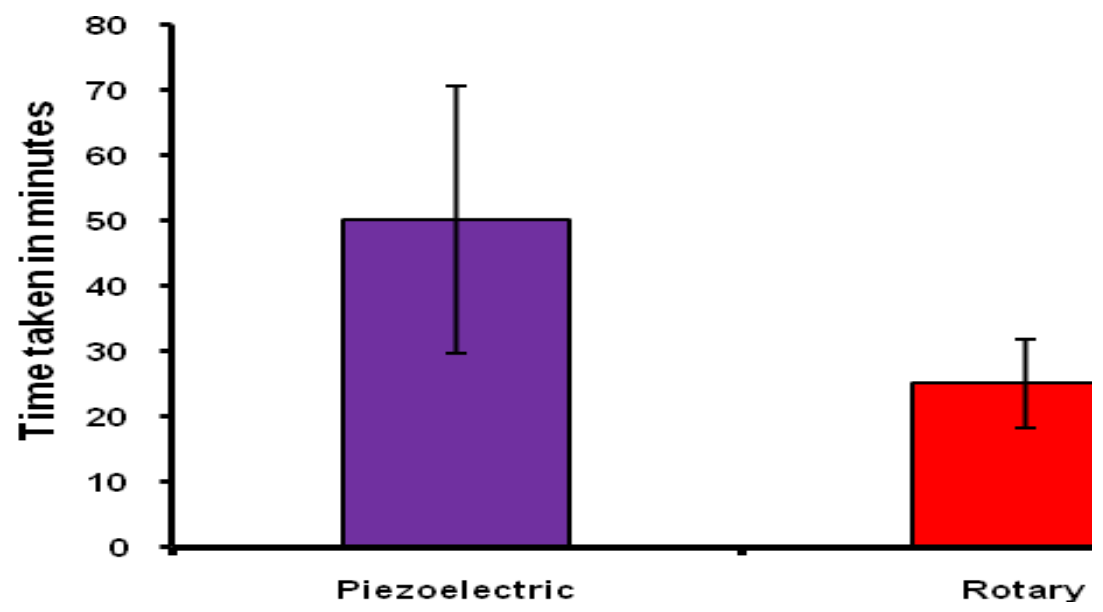

Fig. 1: Graph depicting time taken in minutes between Piezoelectric and Rotary bur

2. Patient satisfaction was evaluated using a grading scale and mixed results were obtained in terms of satisfaction of the procedure, later which were used for tooth removal as shown in Table 4 and Fig. 2.

Table 4: Demonstrates patient satisfaction using grading scale between Piezoelectric and Rotary bur

\begin{tabular}{|l|c|c|c|}
\hline Patient satisfaction grade & $\begin{array}{c}\text { Piezoelectric } \\
(\mathbf{n = 2 0})\end{array}$ & $\begin{array}{c}\text { Rotary } \\
(\mathbf{n = 2 0})\end{array}$ & P value \\
\hline 1: Very satisfied & $6(30.0 \%)$ & $8(40.0 \%)$ & 0.298 \\
\hline 2: Fairly satisfied & $8(40.0 \%)$ & $5(25.0 \%)$ & 0.204 \\
\hline 3: Fairly unsatisfied & $6(30.0 \%)$ & $7(35.0 \%)$ & 0.392 \\
\hline 4: very unsatisfied & 0 & 0 & - \\
\hline
\end{tabular}




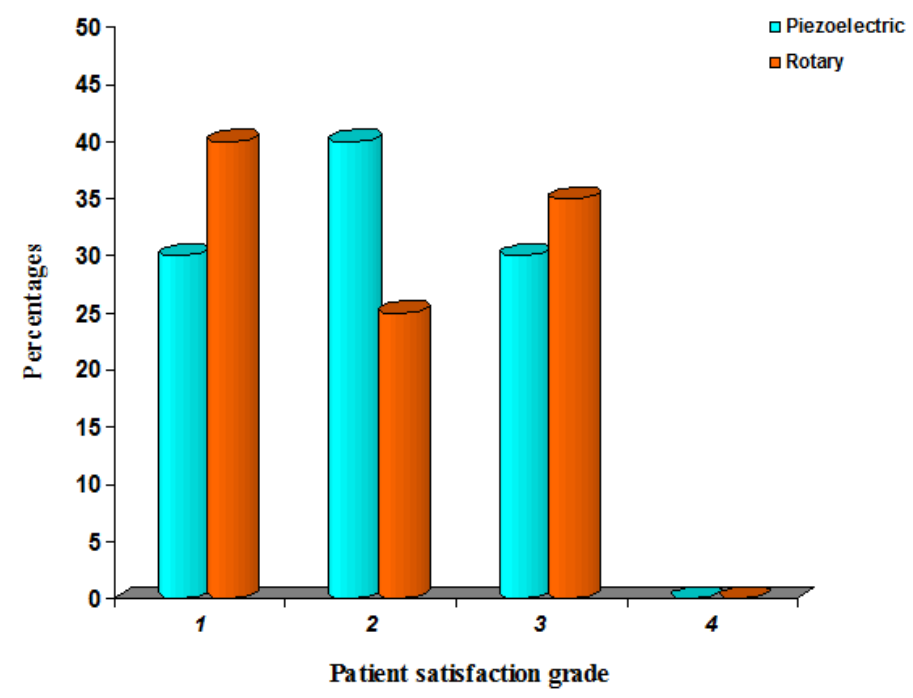

Fig. 2: Depicts percentage of patient satisfaction grade using grading scale between Piezoelectricand Rotary

3. Mouth opening measured in $\mathrm{mm}$ as shown in table $3 \& 3 \mathrm{~A}$, showed a significant difference between the piezoelectric and rotary bur group. The mean of mouth opening on day 3 , day $5 \&$ day 7 was significantly better in the piezoelectric group $(\mathrm{p}<0.01)$ as compared to rotary bur (Table 5 and 5A, Fig. 3).

Table 5: Comparison of mouth opening between Piezoelectric and Rotary

\begin{tabular}{|l|c|c|c|c|c|}
\hline Mouth opening & $\begin{array}{c}\text { Pre-op } \\
(\mathbf{n = 2 0})\end{array}$ & $\begin{array}{c}\text { Day 3 } \\
(\mathbf{n = 2 0})\end{array}$ & $\begin{array}{c}\text { Day 5 } \\
(\mathbf{n = 2 0})\end{array}$ & $\begin{array}{c}\text { Day 7 } \\
(\mathbf{n = 2 0})\end{array}$ & $\begin{array}{c}\text { \% } \\
\text { change }\end{array}$ \\
\hline Piezoelectric & & & & & \\
\hline $0:>35$ (Normal) & $19(95.0 \%)$ & $13(65.0 \%)$ & $16(80.0 \%)$ & $17(85.0 \%)$ & $-10.0 \%$ \\
\hline $1: 25-30$ & $1(5.0 \%)$ & $7(35.0 \%)$ & $4(20.0 \%)$ & $3(15.0 \%)$ & $+10.0 \%$ \\
\hline $2: 20-25$ & 0 & 0 & 0 & 0 & 0.0 \\
\hline $3: 15-20$ & 0 & 0 & 0 & 0 & 0.0 \\
\hline $4:<10$ & 0 & 0 & 0 & 0 & 0.0 \\
\hline Rotary & & & & & \\
\hline $0:>35$ (Normal) & $19(95.0 \%)$ & $7(35.0 \%)$ & $10(50.0 \%)$ & $14(70.0 \%)$ & $+25.0 \%$ \\
\hline $1: 25-30$ & $1(5.0 \%)$ & $10(50.0 \%)$ & $10(50.0 \%)$ & $6(30.0 \%)$ & $-25.0 \%$ \\
\hline $2: 20-25$ & 0 & $3(15.0 \%)$ & 0 & 0 & 0.0 \\
\hline $3: 15-20$ & 0 & 0 & 0 & 0 & 0.0 \\
\hline $4:<10$ & 0 & 0 & 0 & 0 & 0.0 \\
\hline P value & 1.000 & $0.082+$ & $0.096+$ & 0.451 & - \\
\hline
\end{tabular}




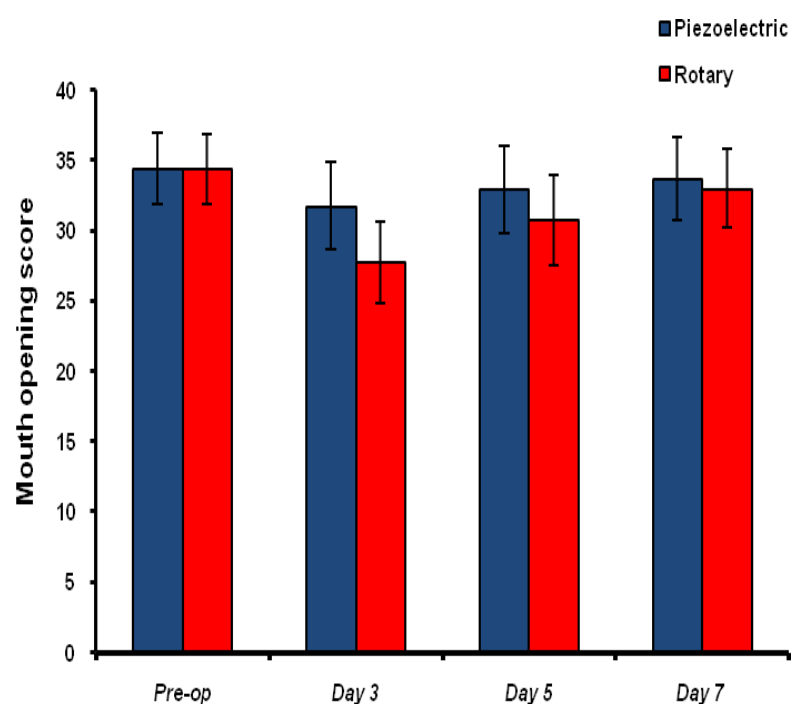

Fig. 3: Depicts mouth opening score between two groups

Table 5A: Comparison of mean score mouth opening for procedure in two groups

\begin{tabular}{|l|l|l|l|}
\hline Mouth opening score & Piezoelectric & Rotary & P value \\
\hline Pre-op & $34.45 \pm 2.54$ & $34.40 \pm 2.46$ & 0.330 \\
\hline Day 3 & $31.75 \pm 3.11$ & $27.75 \pm 2.92$ & $<0.001^{* *}$ \\
\hline Day 5 & $32.95 \pm 3.09$ & $30.75 \pm 3.18$ & $<0.001^{* *}$ \\
\hline Day 7 & $33.70 \pm 2.94$ & $33.00 \pm 2.82$ & $<0.001^{* *}$ \\
\hline
\end{tabular}

4. The severity of pain was recorded using a feedback form of VAS (Table 6). It was found that there is a significant difference between piezoelectric and rotary bur as shown in Fig. 4A and 4B. On day 1 the pain was much less in piezoelectric group as compared with rotary bur group with a $\mathrm{p}$ value of 0.03 . From day 2 to day 6 , there was significant difference among the two groups at the level of $\mathrm{p}<0.01$. On day 7 no significant difference was found among the two groups.

Table 6: Comparison of Grade of pain between two groups using Visual analogue scale

\begin{tabular}{|c|c|c|c|c|c|c|c|c|}
\hline $\begin{array}{c}\text { Grade of } \\
\text { pain }\end{array}$ & Day 1 & Day 2 & Day 3 & Day 4 & Day 5 & Day 6 & Day 7 & $\%$ change \\
\hline \multicolumn{9}{|l|}{ Piezoelectric } \\
\hline 0: no pain & 0 & 0 & 0 & $6(30.0 \%)$ & $12(60.0 \%)$ & $17(85.0 \%)$ & $17(85.0 \%)$ & $+85.0 \%$ \\
\hline 1: slight pain & $3(15.0 \%)$ & $6(30.0 \%)$ & $13(65.0 \%)$ & $11(55.0 \%)$ & $5(25.0 \%)$ & $2(10.0 \%)$ & $2(10.0 \%)$ & $-10.0 \%$ \\
\hline 2: mild pain & $10(50.0 \%)$ & $13(65.0 \%)$ & $7(35.0 \%)$ & $3(15.0 \%)$ & $1(15.0 \%)$ & $1(5.0 \%)$ & $1(5.0 \%)$ & $-45.0 \%$ \\
\hline 3:severe pain & $5(25.0 \%)$ & $1(5.0 \%)$ & 0 & 0 & 0 & 0 & 0 & $-25.0 \%$ \\
\hline $\begin{array}{l}\text { 4: very severe } \\
\text { pain }\end{array}$ & $2(10.0 \%)$ & 0 & 0 & 0 & 0 & 0 & 0 & $-10.0 \%$ \\
\hline $\begin{array}{l}\text { 5.Extremly } \\
\text { Severe pain }\end{array}$ & 0 & 0 & 0 & 0 & 0 & 0 & 0 & 0.0 \\
\hline Total & $20(100.0 \%)$ & $20(100.0 \%)$ & $20(100.0 \%)$ & $20(100.0 \%)$ & $20(100.0 \%)$ & $20(100.0 \%)$ & $20(100.0 \%)$ & 0.0 \\
\hline \multicolumn{9}{|l|}{ Rotary } \\
\hline 0: no pain & 0 & 0 & 0 & $1(5.0 \%)$ & $1(5.0 \%)$ & $5(25.0 \%)$ & $10(50.0 \%)$ & $+50.0 \%$ \\
\hline 1: slight pain & 0 & 0 & $4(20.0 \%)$ & $5(25.0 \%)$ & $10(50.0 \%)$ & $13(65.0 \%)$ & $8(40.0 \%)$ & $+40.0 \%$ \\
\hline 2: mild pain & $2(10.0 \%)$ & $4(20.0 \%)$ & $4(20.0 \%)$ & $6(30.0 \%)$ & $5(25.0 \%)$ & $2(10.0 \%)$ & $2(10.0 \%)$ & $0.0 \%$ \\
\hline 3:severe pain & $12(60.0 \%)$ & $14(70.0 \%)$ & $10(50.0 \%)$ & $8(40.0 \%)$ & $4(20.0 \%)$ & 0 & 0 & $-60.0 \%$ \\
\hline $\begin{array}{l}\text { 4: very severe } \\
\text { pain }\end{array}$ & $6(30.0 \%)$ & $4(20.0 \%)$ & $1(5.0 \%)$ & 0 & 0 & 0 & 0 & $-30.0 \%$ \\
\hline $\begin{array}{l}\text { 5.Extremly } \\
\text { Severe pain }\end{array}$ & 0 & 0 & 0 & 0 & 0 & 0 & 0 & 0.0 \\
\hline Total & $20(100.0 \%)$ & $20(100.0 \%)$ & $20(100.0 \%)$ & $20(100.0 \%)$ & $20(100.0 \%)$ & $20(100.0 \%)$ & $20(100.0 \%)$ & 0.0 \\
\hline P value & $0.003 * *$ & $<0.001 * *$ & $<0.001 * *$ & $0.001 * *$ & $<0.001 * *$ & $<0.001 * *$ & $0.054+$ & \\
\hline
\end{tabular}




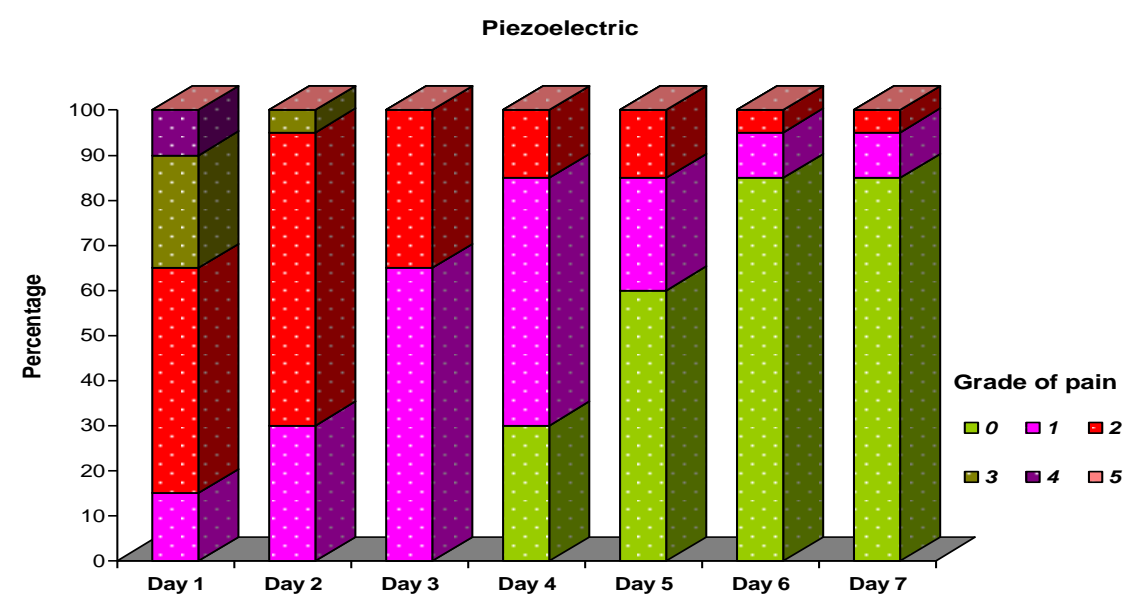

Fig. 4 A: Evaluation of pain in Piezoelectric group

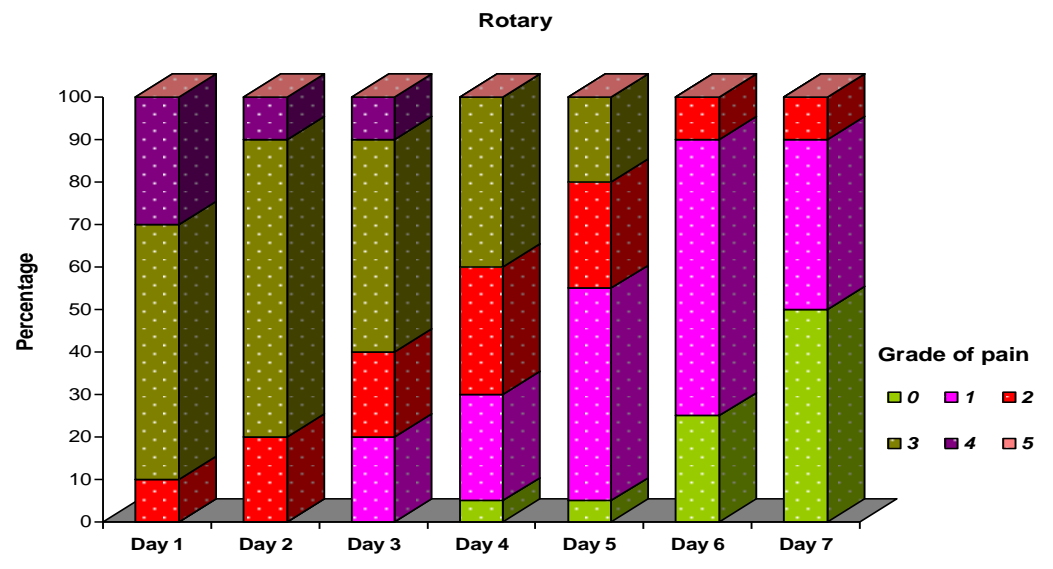

Fig. 4B: Evaluation of pain in Rotary bur group

\section{Discussion}

Impacted third molar tooth removal is the most common procedure performed in oral \& maxillofacial surgery. Morbidity following lower third molar surgery still remains a great concern to many clinicians. ${ }^{9}$ Surgical removal of impacted third molars is a high volume procedure which is performed in hospital and general dental practice, so the incidence of complications have to be as low as possible. The postoperative period following surgical removal is frequently characterized by pain and swelling, sometimes with temporary restricted mouth opening and masticatory incapability. ${ }^{10}$ Pain and swelling are inflammatory responses of the body to acute trauma. It might reflect the formation of prostaglandins and other mediators of pain; swelling from membrane phospholipids, released as a result of surgery and relates to the degree of trauma during the surgery. ${ }^{11}$

When there is an inflammatory reaction, there will be collection of inflammatory fluids within the tissue spaces, which leads to diffuse swelling in the affected areas. This may also aggravate the pain and cause trismus by its pressure effect within the tissue spaces.

Other factors affecting pain and swelling are individual pain threshold, body response and type of wound. The severity of pain might vary among individuals. The severity of trismus and swelling correlates with the degree of trauma during the surgery. Thus, a risk of error is present when the case and control are different individuals. ${ }^{12}$ The present study is a split-mouth study design in which the subjects are served as their own controls.

Over a period of time surgical procedures have been modified to reduce intraoperative and postoperative complications. The surgical method should be one with minimum complication. ${ }^{13}$ Initially bone removal was done by using chisel and mallet. Later rotary instruments were introduced for cutting bone in maxillofacial operations. Rotary instrument produces macrovibrations rotating at the speed of 20,000-35,000 rpm. Rotary instruments are considered as a gold standard for osseous surgeries in maxillofacial 
operations, but many authors quote several disadvantages of using rotary instruments.

Rotating instruments are potentially injurious due to excessive increase in the temperature during osseeus drilling, which can produce marginal osteonecrosis and impair bony regeneration. So, copious irrigation has to be used to reduce the amount of frictional heating with saline irrigation. ${ }^{14}$ Cooling of the osteotomized area during and after the procedure is an important step that contributes to a lower local morbidity. ${ }^{15}$ Thomas Mcfall et al said rotating instruments usually produce considerable amount of heat, and found that they were frequently difficult to control while cutting bone, resulting in inaccurate cuts and undue soft tissue damage. ${ }^{16}$ Absi et al quoted that inflammatory reaction following extraction using rotary bur was severe compared with chisel and took a longer period of time for healing. ${ }^{17}$ Rotary bur produces macrovibrations and extreme noise which might increase fear and stress levels in patients.

Piezoelectric techniques were developed in response to the need for greater precision and safety in bone surgery as compared to that of manual and motorized instruments. The piezoelectric technique was tested in oral surgery during 1970s, when Horton et al examined the recovery process of dogs that had undergone osteotomy using chisel, ultrasonic instrument and low speed bur. The recovery process after chisel and ultrasound instrument was considered similar, whereas in rotary bur, it produced degeneration of cellular elements along the edges, persistence of fibrovascular tissue and a reduced reaction of osteoblasts and osteoclasts. ${ }^{18}$ Piezoelectric surgery was re-evaluated definitely at the end of 1980s and considered as an alternative technique that can be used in osseous oral and maxillofacial surgery, as it produces minor postoperative complications. Piezoelectric surgery is a promising, meticulous and soft tissue sparing system for bone cutting, based on piezoelectric ultrasonic vibrations. It was developed by Italian oral surgeon Tomaso Vercellotti in 1988. A piezoelectric surgery unit is approximately three times as powerful as a conventional ultrasonic dental unit, allowing it to cut highly mineralised cortical bone. ${ }^{19}$

The various advantages of piezoelectric surgery are: ${ }^{20,21}$

a. Nerves, blood vessels and soft tissues are spared by the microvibrations.

b. The precise nature of the instrument allows exact, clean and smooth cut geometries.

c. The selective and thermally harmless nature of the instrument results in low bleeding tendency.

d. Maintains a blood-free operating area because of the cavitation of the irrigation solution, and gives greater visibility, particularly in complex anatomical areas.

e. Produces microvibration and less noise, minimizing psychological stress and fear during osteotomy under local anesthesia.
The present study is done to compare two different instruments i.e., piezoelectric and rotary bur in surgical removal of impacted molar tooth. Intraoperatively, time required and patient satisfaction was evaluated. Postoperatively, mouth opening was measured clinically on day 3 , day 5 and day 7 correlating with preoperative values. Pain was evaluated using a feedback form of VAS for a period of 7 days.

Francesco Sortino et al. (2008) did a clinical study to compare postoperative outcome in surgical removal of third molars treated by piezoelectric and by rotatory osteotomy technique. 100 patients were included in the study and therapeutic protocol was same for both the groups. $24 \mathrm{hrs}$ after surgery, trismus were evaluated in both the groups. The study was concluded by saying that piezoelectric osteotomy produced a reduced amount of trismus $24 \mathrm{hrs}$ after surgery, but a longer surgery time was required when compared with the rotatory osteotomy technique. ${ }^{13}$

In this study, we have been able to compare piezoelectric and rotary instrument for impacted third molar removal by applying the same surgery protocol and measurement methods in both group examined.

In this study, 20 patients have undergone surgical removal of third molars bilaterally, the average time of surgery in piezoelectric group $(50.3 \pm 20.51)$ was higher as compared to rotary bur technique $(25.15 \pm 6.74)$ at the level of $\mathrm{P}<0.001$. Patient satisfaction of the individual procedure evaluated using grading scale from very satisfied to very unsatisfied. In piezoelectric group, $30 \%$ were very satisfied, $40 \%$ were fairly satisfied and $30 \%$ were fairly unsatisfied as compared to rotary bur in which $40 \%$ were very satisfied, $25 \%$ were fairly satisfied and $35 \%$ were fairly unsatisfied.

Postoperative pain was evaluated using a feedback form of visual analog scale for a period of 7 days. The pain was graded as no pain - 0 , slight pain- 1 , mild pain2 , severe pain-3, very severe pain- 4 and extremely severe pain -5 . According to bio statistical analysis, the percent change of pain in piezoelectric group over a period of 7 days was $+85 \%$-grade $0,-10 \%$ - grade 1 , $45 \%$-grade $2,-25 \%$-grade $3,-10 \%$-grade 4 and $0 \%$ grade 5, as compared to percent change of pain in rotary bur group over a period of 7 days which was $+50 \%$-grade $0,+40 \%$ - grade $1,0 \%$-grade $2,-60 \%$ grade $3,-30 \%$-grade 4 , and $0 \%$ - grade 5 . These values give an inference that the amount of pain experienced by piezoelectric group was less as compared to rotary bur technique over a period of 7 days.

The mouth opening was evaluated by measuring the Interincisal distance. Mean values for mouth opening in piezoelectric group were on day 3$31.75 \pm 3.11$, day $5-32.95 \pm 3.09$, day $7-33.70 \pm 2.94$ as compared with rotary bur group in which they were on day $3-27.75 \pm 2.92$, day $5-30.75 \pm 3.18$, day 7$33.00 \pm 2.82$. The mouth opening was much better in piezoelectric group as compared to rotary bur group at the level of $\mathrm{P}<0.001$. 


\section{Conclusion}

The conclusions drawn from this study are:

1. Piezoelectric device is a promising, meticulous, innovative ultrasonic technique for safe and effective bone removal when compared with rotary technique because of the absence of macrovibrations and noise, its ease of use and safer cutting, particularly in anatomical areas closer to neurovascular bundles.

2. Although the time required for the procedure was very long with piezoelectric technique, the postoperative complications such as pain andtrismus were lesser with the use of piezoelectric instrument than that of rotary instrument. Even with a longer duration of time, the use of piezoelectric device allowed a more comfortable postoperative time for patients when compared with rotary technique. .

3. One should master the way to use piezoelectric device as it is a highly technique sensitive instrument. It requires minimum pressure for removal of bone and working is paused for every $45 \mathrm{sec}$; excessive pressure leads to breakage of instrument and increases the temperature of the tip, which might lead to bony damage.

Thus, we conclude piezoelectric instrument is better alternative for removal of impacted tooth than rotary instruments. Extensive studies are required to be conducted for its different uses in osseous surgeries, so that its range of applications can be widened with fewer limitations in the field of oral and maxillofacial surgery with improving patient's compliance and satisfaction.

\section{Conflict of Interest: None}

\section{References}

1. Waseem J, Mohammed El-Maaytah, Brian S, Bilquis B, Tahwinder U, Sapna D. Experience versus complication rate in third molar surgery. Head Face Med 2006;2:14.

2. Chi HB, Edward B S, Thomas BD. Types, frequencies, and risk factors for complications after third molar extraction. J Oral Maxillofac Surg 2003;61(12):1379-89.

3. Chiapasco M, De C L, Marrone G. Side effects and complications associated with third molar surgery. Oral Surg Oral Med Oral Pathol 1993;76(4):412-20.

4. Kafas P, Jerjes W, Hopper C, Dalabiras S. Complications following lower third molar surgery in a specific age group: A prospective study. Surg J 2007;2(4):50-54.

5. Ribeiro Junior PD, Barleto CV, Ribeiro DA, Matsumoto MA. Evaluation of different rotary devices on bone repair in rabbits. Braz Dent J 2007;18(3):215-19.

6. Praveen G, Rajesh P, Neelakandan RS, Nandagopal CM. Comparision of morbidity following the removal of mandibular third molar by lingual split, surgical bur and simplified split bone technique. Indian J Dent Res 2007;18(1):15-18.
7. Pavlikova G, Foltan R, Horka M, Hanzelka T, Borunska $\mathrm{H}$, Sedy J. Piezosurgery in oral and maxillofacial surgery. Int J Oral Maxillofac Surg 2011; 40(5):451-57.

8. Mauro L, Flavio A, Raffaele V, Luigi F R. Piezoelectric surgery: Twenty years of use. Br J Oral Maxillofac Surg 2008;46(4):265-69.

9. Felix NC, Chima O, Dauda B. A comparative study of the effect of using a rubber drain on postoperative discomfort following lower third molar surgery. Int J Oral Maxillofac Surg 2008;37(4):341-44.

10. Pasqualini D, Cocero N, Castella A, Mela L, Bracco P. Primary and secondary closure of the surgical wound after removal of impacted mandibular third molars: Acomparative study. Int J Oral Maxillofac Surg 2005;34(1):52-57.

11. Abel G, Francisco GS, Jose GR, Mercedes GT. Trismus and pain after removal of impacted third molars. $J$ Oral Maxillofac Surg 1997;55(11):1223-1226.

12. Anil KD, Murali KT, Vinod N, Avinash S. Influence of primary and secondary closure of surgical wound after impacted mandibular third molar removal on post operative pain and swelling- A comparative and split mouth study. J Oral Maxillofac Surg 2010;68(2):309-12.

13. Francesco S, Eugenio P, Veronica M. The piezoelectric and rotatory bur osteotomy technique in impacted third molar surgery: A comparision of postoperative recovery. J Oral Maxillofac Surg 2008;66(12):2444-48.

14. Robiony M, Polini F, Costa F, Vercellotti T, Politi M. Piezoelectric bone cutting in multipiece maxillary osteotomies. J Oral Maxillofac Surg 2004;62(6):759-61.

15. Paulo D, Vespasiano B, Araki R, Akemi M. Evaluation of different rotary devices on bone repair in rabbits. Braz Dent J 2007;18(3):215-19.

16. Thomas AM, George MY, George WB. Comparision of the cutting effect on bone of an ultrasonic cutting device and rotary burs. J Oral Surg 1961; 19:200-209.

17. Absi EG, Shepherd JP. A comparision of morbidity following the removal of lower third molars by the lingual split and surgical bur methods. Int J Oral Maxillofac Surg 1993;22(3):149-153.

18. John EH, Thomas MT, Larry DW. The healing of surgical defects in alveolar bone produced with ultrasonic instrumentation, chisel and rotary bur. Oral Surg Oral Med Oral Pathol 1975;39(4)4:536-46.

19. Stefan S, Johannes K, Andreas F, Robert S, Hans-Florian Z. Intraoral piezosurgery: preliminary results of a new technique. J Oral Maxillofac Surg 2005;63(9):1283-7.

20. Georg E, Johannes K, Julia B, Stefan H. Piezosurgery: an ultrasound device for cutting bone and its use and limitations in maxillofacial surgery. Br J Oral Maxillofac Surg 2004:42(5):451-53.

21. Robiony M, Polini F, Costa F, Vercellotti T, Politi M. Piezoelectric bone cutting in multipiece maxillary osteotomies. J Oral Maxillofac Surg 2004;62(6):759-61.

How to cite the article: Pradeep PS, Malegowda SS, Muhsina K, Anchan PS, Asal Irfan P. Piezoelectric Surgery Versus Conventional Rotary Surgical Technique for Surgical Removal of Impacted Mandibular Third Molars: A prospective study. J Dent Specialities 2018;6(2):92-99. 